\title{
Lung Carcinoma Cells Secrete Exosomal MALATI to Inhibit Dendritic Cell Phagocytosis, Inflammatory Response, Costimulatory Molecule Expression and Promote Dendritic Cell Autophagy via AKT/mTOR Pathway
}

This article was published in the following Dove Press journal: OncoTargets and Therapy

\author{
Yanyan Liu (D) \\ Zhucheng Yin ${ }^{2}$ \\ Ping $L u^{2}$ \\ Yifei $\mathrm{Ma}^{2}$ \\ Bo Luo ${ }^{3}$ \\ Lanxin Xiang ${ }^{4}$ \\ Wangli Zhang ${ }^{4}$ \\ Yu $\mathrm{He}^{5}$ \\ Xinjun Liang ${ }^{2}$ \\ 'Division of Nephrology, Tongji Hospital, \\ Tongji Medical College, Huazhong \\ University of Science and Technology, \\ Wuhan, Hubei, People's Republic of \\ China; ${ }^{2}$ Department of Medical \\ Oncology, Hubei Cancer Hospital, Tongji \\ Medical College, Huazhong University of \\ Science and Technology, Wuhan, Hubei, \\ People's Republic of China; ${ }^{3}$ Department \\ of Radiotherapy, Hubei Cancer Hospital, \\ Tongji Medical College, Huazhong \\ University of Science and Technology, \\ Wuhan, Hubei, People's Republic of \\ China; ${ }^{4}$ School of Life Science and \\ Technology, Huazhong Agricultural \\ University, Wuhan, Hubei, People's \\ Republic of China; ${ }^{5}$ Department of \\ Orthopaedics, Union Hospital, Tongji \\ Medical College, Huazhong University of \\ Science and Technology, Wuhan, Hubei, \\ People's Republic of China
}

Correspondence: Xinjun Liang; Yu He Email doctorlxj@163.com; heyu6666@I63.com
Objective: To investigate the potential mechanism underlying the effect of lung carcinoma cell-derived exosomes on dendritic cell function.

Materials and Methods: $\mathrm{C} 57 \mathrm{BL} / 6$ (B6) mice were randomly divided into five groups: control, dendritic cell (DC), DC-NC, DC-siMALAT1, and siMALAT1. Tumor cell proliferation was measured by Ki-67 staining. LLC cells were divided into control, NC, and siMALAT1 groups, and exosomes secreted by each group were labeled as PEX, PEXN, and PEX-si, respectively. Exosomes and autophagic vacuoles were observed by transmission electron microscopy. MALAT1 expression in LLC, A549, and Beas-2b cells was examined by RT-PCR. The expression of IFN- $\gamma$, IL-12, IL-10, and TGF- $\beta$ was observed by Elisa assay. Flow cytometry was used to observe the phagocytic function of DCs, costimulatory molecule expression, and $\mathrm{T}$ cell proliferation and differentiation. The protein expression of $\mathrm{p}-\mathrm{AKT}$, AKT, p-mTOR, mTOR, ALIX, TSG101, and CD63 was detected by Western blot.

Results: Compared with Beas-2b cells, MALAT1 expression was significantly increased in both LLC and A549 cells and in their secreted exosomes, and LLC cells showed the highest expression of MALAT1 $(\mathrm{P}<0.05)$. Tumor cell proliferation and tumor volume were significantly decreased in the siMALAT1 and DC-siMALAT1 groups compared to those in the control group. DC phagocytosis, inflammatory response, costimulatory molecule expression, and $\mathrm{T}$ cell proliferation in the siMALAT1 and PEX-si groups were significantly enhanced $(\mathrm{P}<0.05)$, while $\mathrm{DC}$ autophagy and $\mathrm{T}$ cell differentiation were reduced $(\mathrm{P}<$ 0.05). The levels of p-AKT, AKT, p-mTOR, and mTOR in the PEX and PEXN groups were increased compared with those in the control group, while those in the siMALAT1 and PEXsi groups were significantly decreased $(\mathrm{P}<0.05)$.

Conclusion: Inhibition of MALAT1 expression in LLC-derived exosomes promoted DC function and $\mathrm{T}$ cell proliferation and suppressed $\mathrm{DC}$ autophagy and $\mathrm{T}$ cell differentiation, suggesting that MALAT1 inhibition may be a potential strategy for the clinical treatment of lung cancer.

Keywords: MALAT1, dendritic cells, AKT, mTOR, autophagy

\section{Plain Language Summary}

1. Dendritic cells are the most powerful antigen-presenting cells in the body and have the ability to induce the production of specific cytotoxic T lymphocytes. LLCs secrete exosomal 
MALAT1 to inhibit DC function and T cell proliferation, while promoting $\mathrm{DC}$ autophagy and $\mathrm{T}$ cell differentiation. 2. Metastasis-associated lung adenocarcinoma transcript 1 (MALAT1) plays an important role in tumorigenesis and development,16 and its expression is abnormally high in various tumors including lung cancer. In this study, we found that MALAT1 may be a key molecule affecting the function of DCs in LLCs. 3. Inhibition of MALAT1 in LLC-derived exosomes promoted DC phagocytosis, inflammatory response, costimulatory molecule expression, and $\mathrm{T}$ cell proliferation but suppressed DC autophagy and $\mathrm{T}$ cell differentiation. 4. Lung cancer is one of the most common malignancies worldwide, with the highest fatality rate among all types of malignant tumors. Treatment methods include radiotherapy, chemotherapy, and surgical intervention, but their curative effect remains unsatisfactory. Through this study, we verify that MALAT1 can be a potential strategy for the clinical treatment of lung cancer.

\section{Introduction}

Lung cancer is one of the most common malignancies worldwide, with the highest fatality rate among all types of malignant tumors and a five-year survival rate of lower than $20 \%{ }^{1,2}$ Treatment methods include radiotherapy, chemotherapy, and surgical intervention, but their curative effect remains unsatisfactory. As a characteristic of tumors, immune escape is an important mechanism of tumor occurrence, and targeting tumor immune escape is the mainstream strategy in tumor immunotherapy. ${ }^{3}$ Dendritic cells (DCs) are the most powerful antigen-presenting cells in the body and have the ability to induce the production of specific cytotoxic T lymphocytes. Studies have shown that the occurrence, development, and prognosis of malignant tumors are associated with DCs. Because of the decreased number of DCs in tumor and adjacent tissues, DCs cannot present tumor-related antigens and activate cytotoxic $\mathrm{T}$ lymphocytes to carry out specific immune killing on tumor cells. The purpose of immunotherapy is to initiate the tumor-immune cycle, ${ }^{4}$ wherein inhibiting the immune evasion of tumor cells and improving DC function play important roles in tumor treatment.

The tumor microenvironment plays a critical role in the process of tumorigenesis, drug sensitivity, metastasis, and recurrence. Exosomes are vesicles with a diameter of 30-100 $\mathrm{nm}$ that are secreted by various stem cells and progenitor cells, forming an essential part of the tumor microenvironment. Exosomes regulate cell-to-cell communication through factors such as nucleic acids, proteins, and active lipids contained within vesicles. $^{5-8}$ Long non-coding RNAs (lncRNAs) are a class of RNAs with a length of greater than 200 nucleotides that lack protein-coding ability. ${ }^{9}$ Studies have found that lncRNAs participate in various biological processes by regulating gene expression. ${ }^{10-12}$ Imbalance of IncRNA expression has been observed in tumors and is related to tumor prognosis. ${ }^{13-15}$ Metastasis-associated lung adenocarcinoma transcript 1 (MALAT1) plays an important role in tumorigenesis and development, ${ }^{16}$ and its expression is abnormally high in various tumors including lung cancer. Zhang et al found that the expression of MALAT1 in exosomes secreted by tumor cells was abnormally high. ${ }^{17}$ DCs are regulated by a variety of lncRNAs, and DC-derived lncRNAs can affect the differentiation of DCs and inhibit antigen presentation. ${ }^{18,19}$ MALAT1 carried by exosomes that are secreted by different cells can regulate the function of target cells. ${ }^{17,20,21}$ However, whether exosomes secreted by lung cancer cells carry MALAT1, which affects the function of DCs, has not yet been reported.

Autophagy is an evolutionarily conserved cell degradation process that maintains the stability of immune response, participates in the regulation of cell function, and affects the survival and proliferation of immune cells. ${ }^{22,23}$ The autophagic activity of DCs is necessary for their ability to activate T cells. Studies have found that treatment of DCs with tumor-derived exosomes can cause functional changes in DCs. ${ }^{24} \mathrm{AKT} /$ mammalian target of rapamycin (mTOR) is highly expressed in a variety of tumor cells, including lung cancer cells, and is involved in regulating their proliferation and autophagy. However, whether exosomes released by lung tumor cells affect DC autophagy and thus affect the function of DCs is rarely reported.

In this study, we examined the expression of MALAT1 in lung cancer cells and their secreted exosomes and studied its effects on DC phagocytosis, inflammatory factor expression, and DC-mediated T cell activation. We constructed an in vivo xenograft model to investigate the proliferation of tumor cells and to elucidate the possible mechanism of tumor cell immune evasion, providing a theoretical basis for further improving the effect of immunotherapy.

\section{Materials and Methods Cell Culture}

The lung cancer cell lines LLC and A549 and pulmonary epithelial cells Beas- $2 b$ were kindly provided by the Stem Cell Bank, Chinese Academy of Sciences. Cells were cultured in RPMI 1640 medium (SH30809.01B, Hyclone) or BEGM Bullet Kit (CC3170, Lonza) supplemented with 10\% fetal bovine serum $(10,270-106$, Gibco) in an atmosphere containing $5 \% \mathrm{CO} 2$ and $95 \%$ air at $37^{\circ} \mathrm{C}$. The medium was replaced every 
24 hours and the cells were subcultured or cryopreserved when the confluence reached $70-80 \%$.

Mouse bone marrow-derived DCs were isolated and cultured according to previously reported protocols. ${ }^{25,26}$ After C57BL/6 (B6) mice were anesthetized, the tibia and femur were extracted under aseptic conditions and the medullary cavity was washed with $1 \mathrm{~mL}$ of RPMI 1640 medium. The bone marrow cell suspension was centrifuged at $1500 \mathrm{rpm}$ for $10 \mathrm{~min}$, and $3 \mathrm{~mL}$ of red blood cell lysate was added and centrifuged at $1500 \mathrm{rpm}$ for $5 \mathrm{~min}$. The cells were cultured in 6 -well plates at $1 \times 10^{6}$ cells per well, and granulocyte-macrophage colony-stimulating factor (GM-CSF) and interleukin (IL)-4 were added at $20 \mathrm{ng} / \mathrm{mL}$ and $10 \mathrm{ng} / \mathrm{mL}$, respectively. The cells were incubated at $37^{\circ} \mathrm{C}$ in $5 \%$ $\mathrm{CO} 2$ for $48 \mathrm{~h}$, after which the medium was replaced with complete medium containing GM-CSF and IL-4 was added. The cells were stained with mouse CD11c monoclonal antibodies and DCs were identified using flow cytometry. DCs were successfully isolated if the proportion of CD11c+ cells was greater than $85 \%$.

T cells were isolated from the spleen of C57BL/6 (B6) mice according to the method reported by Jiang et al. ${ }^{27}$ The expression of CD3 was detected by flow cytometry to determine the purity of $\mathrm{T}$ cells. A CD3+ proportion of greater than $85 \%$ indicated high $\mathrm{T}$ cell purity, suggesting that the isolation was successful.

\section{Animals}

Thirty male C57BL/6 (B6) mice (16-20 g) were purchased from the Hubei Province Disease Control Center (no. 211002300042744). The animals were maintained in a specific-pathogen-free laboratory in a regular $12 \mathrm{~h} / 12$ $\mathrm{h}$ light/dark cycle at an average temperature of $24.5^{\circ} \mathrm{C}$ and $50-60 \%$ relative humidity. All protocols and procedures were performed in accordance with the National Institutes of Health Guide for the Care and Use of Laboratory Animals and were approved by the Animal Care and Use Committee, Wuhan Myhalic Biotechnology Co. Ltd.

Eight days before the experiment, $200 \mu \mathrm{L}$ of LLCs were injected subcutaneously at $1 \times 10^{7}$ cells $/ \mathrm{mL}$ into the right temporal region of the mice. The mice were randomly divided into five groups ( $\mathrm{n}=6$ per group): Control, DC, DC-siMALAT1, DC-negative control (NC), and siMALAT1. Mice in the DC, DC-siMALAT1, and DC-NC groups were intratumorally injected with the respective DCs at $1 \times 10^{5}$ cells $/ \mathrm{mL}$ on days 8,11 , and 14 , and intramuscular injection was performed at $1 \times 10^{5}$ cells/mL on days 8,11 , and 14 in the siMALAT1 group.
The length and width of the tumors were measured every other day for 21 consecutive days. Tumor tissue was collected after the experiment and tumor cell proliferation was measured according to the method of Tang et al. ${ }^{28}$

\section{Isolation and Identification of Exosomes Derived from LLC, A549, and Beas-2b Cells}

Exosomes were extracted according to the instructions of an exosome extraction kit (EXOTC50A-1, SBI). After $48 \mathrm{~h}$ of cell culture, the medium was centrifuged at $4{ }^{\circ} \mathrm{C}$ at $3000 \times \mathrm{g}$ for 15 minutes. Exosome precipitation solution was added, kept at $4^{\circ}$ $\mathrm{C}$ overnight, and centrifuged at $1500 \times \mathrm{g}$ for 15 minutes. After the supernatant was discarded, $2 \mathrm{~mL}$ of phosphate-buffered saline (PBS) was added and the exosomes were stored at -80 ${ }^{\circ} \mathrm{C}$. To identify the exosomes, the exosome suspension was added to a copper mesh and after 5 minutes, uranyl acetate was added in the absence of light. After 5 minutes, the sample was washed with double-distilled water and observed under a transmission electron microscope (HT7700, Hitachi).

Construction of MALAT1 interference vectors and exosome extraction

MALAT1 interference vectors pSICOR (shMALAT1-1: 5'-TCCACTTGATCCCAACTCATC-3'; shMALAT1-2: 5'-A TAACGAAGAGATACCTGTCT-3'; shMALAT1-3: 5'-TGT ACTATCCCATCACTGAAG-3'; shMALAT1-3: 5'-ATCTG ATTCTAACAGCACATC-3') were purchased from Addgene (Cambridge, MA, USA). T293 cells were seeded in T25 petri dishes and when they reached $70-80 \%$ confluence, they were transfected using Lipofectamine 2000 reagent according to the manufacturer's instructions. The transfection efficiency was detected by quantitative reverse transcriptase polymerase chain reaction (qRT-PCR).

LLCs were divided into control, $\mathrm{NC}$, and si-MALAT1 groups. After 72 hours of infection, the culture medium was collected and exosomes were separated and labeled as PEX (control), PEXN (NC), and PEX-si (si-MALAT1), respectively.

\section{Transmission Electron Microscopy (TEM)}

Cells were pre-fixed with $2.5 \%$ glutaraldehyde (10-20 times the tissue volume) at $4{ }^{\circ} \mathrm{C}$ for $30 \mathrm{~min}$, fixed with $1 \%$ osmic acid for $1 \mathrm{~h}$, dehydrated, soaked in a 1:1 mixture of acetone:epoxy at $40{ }^{\circ} \mathrm{C}$ for $6 \mathrm{~h}$, fixed with pure epoxy resin at $40{ }^{\circ} \mathrm{C}$ for $4 \mathrm{~h}$, and embedded. The samples were then sectioned and subjected to double staining and lead citrate staining for $15 \mathrm{~min}$. After rinsing with double-distilled water, the ultrastructure of the mitochondria was observed using TEM (HT7700, Hitachi). 


\section{Enzyme-Linked Immunosorbent Assay (ELISA)}

The expression of interferon (IFN)- $\gamma$, IL-12, IL-10, and transforming growth factor (TGF)- $\beta$ was observed by ELISA. Samples and enzyme were added to a test tube and incubated at $37^{\circ} \mathrm{C}$ according to the experimental instructions. The reaction was stopped $10 \mathrm{~min}$ after color appeared and the optical density was measured at $450 \mathrm{~nm}$.

\section{Flow Cytometry}

Cells were resuspended in $100 \mu \mathrm{L}$ of flow cytometry buffer and mixed with $2 \mu \mathrm{L}$ of dextran (46945, Sigma), CD3 (85-11-0114-81, $0.5 \mu \mathrm{g} /$ test, eBioscience), CD80 (85-120801-81, $0.25 \mu \mathrm{g} /$ test, eBioscience), or CD11c (12-0116-41, $5 \mu \mathrm{L} /$ test, eBioscience). The tubes were incubated at $4^{\circ} \mathrm{C}$ for $45 \mathrm{~min}$ in the dark, and after the addition of $2 \mu \mathrm{L}$ of flow dyeing buffer to each tube, they were centrifuged at $4^{\circ} \mathrm{C}$ at 300 $\times \mathrm{g}$ for $5 \mathrm{~min}$. The supernatant was discarded and $400 \mu \mathrm{L}$ of flow cytometry dyeing buffer was added to each tube. Flow cytometry was performed (NovoCyte, ACEA) and the results were analyzed using NovoCyte software.

To examine the effect of DCs on T cell proliferation, DCs were divided into the following groups: Control, NC (empty vector), PEX (MALAT1 exosomes), PEXN (MALAT1 exosome-NC), PEX-si (MALAT1), and siMALAT1 (MALAT1siRNA). After $24 \mathrm{~h}$ of virus intervention, mitomycin C (10 mg/mL, A4452, Apexbio) was added and the DCs were co-cultured with T cells at a DC:T ratio of 10:1, 20:1, or 40:1 for $2 \mathrm{~h}^{29}$ The procedure was performed in accordance with the BeyoClick $^{\mathrm{TM}}$ Edu-488 cell proliferation assay kit (C0071S, Beyotime) and analyzed by flow cytometry. The ability of DCs to regulate $\mathrm{T}$ cell differentiation was detected by adding $2 \mu \mathrm{L}$ of CD4 (85-11-0041-81, $0.25 \mathrm{~g} /$ test, eBioscience) and CD25 (8517-0251-81, $5 \mu \mathrm{L} /$ test, eBioscience). After membrane rupture and resuspension, $2 \mu \mathrm{L}$ of foxp3 antibodies (85-12-4771-82, $0.25 \mathrm{~g} /$ test, eBioscience) were added and incubated at $4^{\circ} \mathrm{C}$ for $45 \mathrm{~min}$. Then $400 \mu \mathrm{L}$ of flow dyeing buffer was added and flow cytometry was performed (NovoCyte, ACEA). The results were analyzed using NovoCyte software.

\section{qRT-PCR}

RNA was extracted using Trizol reagent according to the manufacturer's procedures and cDNA was synthesized using a reverse transcriptase kit (TAKARA, Osaka, Japan). qPCR was performed with a real-time system (BIO-RAD, CA, USA) using the SYBR Green PCR Kit (KM4101, KAPA Biosystems, Massachusetts, USA). Each qPCR reaction $\left(95^{\circ} \mathrm{C}, 3\right.$ min for denaturation; $95^{\circ} \mathrm{C}, 5 \mathrm{~s}$ and $56^{\circ} \mathrm{C}, 10 \mathrm{~s}$, and $72{ }^{\circ} \mathrm{C}, 25 \mathrm{~s}$ for 39 cycles; $65^{\circ} \mathrm{C}, 5 \mathrm{~s}$ and $95^{\circ} \mathrm{C}, 50 \mathrm{~s}$ ) was performed in duplicate. The results were analyzed by the $2^{-\Delta \Delta \mathrm{Ct}}$ method. The primers were designed and configured by Nanjing Kingsy Biotechnology Co., Ltd. and are listed in Table 1.

\section{Western Blot}

Protein extracts $(10$ or $20 \mu \mathrm{g})$ prepared from LLCs were separated by $6 \%$ or $12 \%$ sodium dodecyl sulfatepolyacrylamide gel electrophoresis and transferred to polyvinylidene fluoride membranes (IPVH00010, Millipore, Wisconsin, USA). The membranes were blocked with 5\% milk in Tris-buffered saline (pH 7.6) containing $0.1 \%$ Tween 20 and incubated overnight at $4{ }^{\circ} \mathrm{C}$ with specific primary antibodies against the following proteins: ALG-2-Interacting protein X (ALIX, 1:1000, PAB33277, Bioswamp, China), TSG101 (1:1000, PAB33278, Bioswamp), CD63 (1:1000, PAB33929, Bioswamp), beclin-1 (1:1000, PAB35215, Bioswamp), LC3I/II (1:1000, MAB37400, Bioswamp), p62 (1:1000, PAB35470, Bioswamp), AKT (1:1000, PAB30596, Bioswamp), p-AKT (1:1000, PAB43158-P, Bioswamp), mTOR (1:1000, PAB33332, Bioswamp), p-mTOR (1:1000, PAB36313-P, Bioswamp), and GAPDH (1:1000, PAB36269, Bioswamp). After three washes with PBS/Tween 20, the membranes were incubated with horseradish peroxidaseconjugated secondary goat anti-rabbit IgG (1:20000, SAB43714, Bioswamp) for $2 \mathrm{~h}$ at room temperature. Protein bands were visualized by enhanced chemiluminescence color detection (Tanon-5200, TANON, Shanghai, China) and analyzed using AlphaEase FC gel image analysis software.

\section{Immunohistochemistry}

Sections were incubated at $65^{\circ} \mathrm{C}$ for $1 \mathrm{~h}$, transparentized with xylene, immersed in alcohol, subjected to antigen retrieval, and incubated with $3 \% \mathrm{H}_{2} \mathrm{O}_{2}$ to remove endogenous peroxidases. Blocking was performed in $0.5 \%$ bovine serum albumin, after

Table I Primer Sequences

\begin{tabular}{|l|l|}
\hline Primer & Sequence $\mathbf{( 5}^{\prime}$-3') \\
\hline M-MALATI-F & TGGCTTGTCAACTGCG \\
M-MALATI-R & TCAAGGAATGTTACCG \\
H-MALATI-F & TAACCAGGCATAACAC \\
H-MALATI-R & CGAAGACACAGAGACC \\
M-GAPDH-F & CCTTCCGTGTTCCTAC \\
M-GAPDH-R & GACAACCTGGTCCTCA \\
H-GAPDH-F & CCACTCCTCCACCTTTG \\
H-GAPDH-R & CACCACCCTGTTGCTGT \\
\hline
\end{tabular}


which the sections were incubated with primary antibodies against Ki67 (1:50, PAB30684, Bioswamp) overnight at $4{ }^{\circ} \mathrm{C}$. Positive staining was assessed using the MaxVision ${ }^{\mathrm{TM}}$ HRPPolymer HRP Detection System (KIT-5020, MXB, China). Six sections were stained from each group and five areas were randomly selected from each section for image acquisition. The integrated optical density was calculated in Image Pro-Plus 6.0.

\section{Statistical Analysis}

Data are expressed as the mean \pm standard deviation (SD). To analyze the differences between groups, data comparison was performed by $t$-tests and one-way analysis of variance using SPSS 22 statistical software. $\mathrm{P}<0.05$ was considered statistically significant.

\section{Results}

\section{Identification of Exosomes Derived from LLC, A549, and Beas-2b Cells}

Exosomes derived from LLC, A549, and Beas-2b cells were identified by TEM and Western blot. As shown in Figure 1A, the exosomes were cup-shaped with diameters ranging from 50 to $200 \mathrm{~nm}$. We further detected the expression levels of ALIX, TSG101, and CD63, which are surface markers of exosomes. Almost no expression of these markers was detected in the culture medium, but positive expression was found in exosomes (Figure 1B), suggesting the successful isolation of exosomes.

\section{MALATI Expression in LLC, A549, and Beas-2b Cells}

Compared with Beas- $2 \mathrm{~b}$ cells, the expression of MALAT1 was significantly increased in both LLC and A549 cells and in their secreted exosomes (Figure 2), with LLCs showing the highest MALAT1 expression $(P<0.05$, $P=0.031, P=0.029$ ). Thus, we selected LLCs for the subsequent experiments.

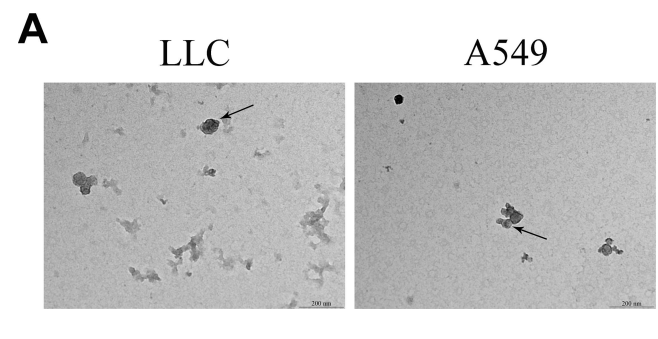

Figure I Identification of exosomes derived from LLC, A549, and Beas-2b cells. (A) Detection of exosomes by TEM (scale bar $=500 \mathrm{~nm})$. Arrows indicate exosomes. (B) Protein expression of ALIX, TSGI0I, and CD63 was measured by Western blot.

\section{Controls for Interference Expression}

To determine the efficiency of the MALAT1 interference vector, the expression of MALAT1 was evaluated in the control, NC, and si-MALAT1 (1-4) groups (Figure 3A). The results showed that the expression of MALAT1 in the si-MALAT1 groups was significantly decreased compared to that in the control and NC groups $(P<0.05, P=0.014$, $P=0.002, P=0.003, P=0.008)$. Among them, si-MALAT1-3 selected for the subsequent experiments. We then characterized the exosomes secreted by cells from each group. As revealed in Figure 3B, the exosomes were cup-shaped with diameters ranging from 50 to $200 \mathrm{~nm}$, and showed positive expression of ALIX, TSG101, and CD63 (Figure 3C).

\section{Inhibition of MALATI Suppressed Tumor Growth in vivo}

Compared with the control group, siMALAT1 and DCsiMALAT1 reduced the volume of tumors formed by LLCs, and the inhibitory effect increased with time (Figure 4A). At the end of the in vivo experiment, we collected tumor tissues and examined the change in tumor proliferation ability by Ki-67 staining. Compared with the control group, tumor proliferation was significantly decreased in the other groups $(P<0.05$, $P=0.000, P=0.001$ ), the Ki-67 index in each group showed the similar trends (Figure 4B). In particular, siMALAT1 induced the greatest reduction in proliferation, suggesting that inhibition of MALAT1 suppressed tumor proliferation.

\section{Isolation and Identification of DCs and T Cells}

As shown in Figure 5A, the percentage of CD11c + cells was $92.51 \%$, suggesting that DCs were successfully isolated. In terms of $\mathrm{T}$ cells, the percentage of CD3+ cells was $96.01 \%$ (Figure 5B), revealing that $\mathrm{T}$ cells were also successfully isolated.

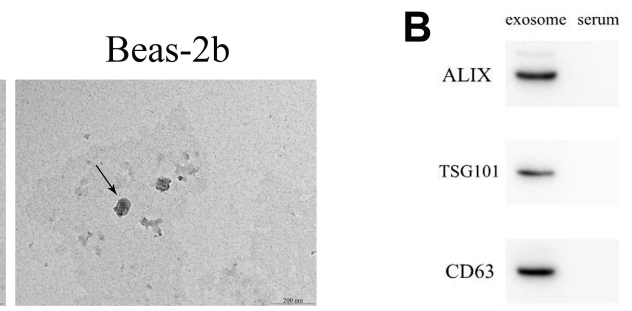
showed the strongest interference efficiency and was 


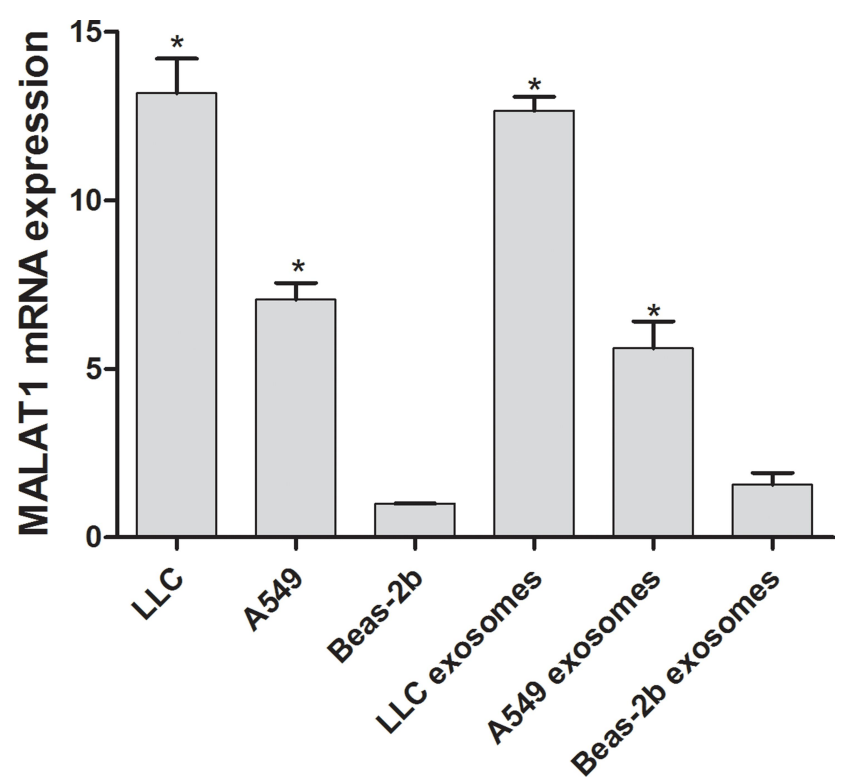

Figure 2 qRT-PCR measurement of MALATI expression. The results are presented as the mean $\pm S D, n=3$. $* P<0.05$ vs Beas $-2 b$.

\section{LLC-Derived Exosomes Inhibited DC Phagocytosis, Inflammatory Response, and Costimulatory Molecule Expression}

To investigate the effect of LLC-derived exosomes on DC phagocytosis and CD80 expression, flow cytometry was carried out (Figure 6A and B). Compared with the control, CD80 expression and phagocytic function were significantly decreased in the PEX and PEXN groups but were increased in the siMALAT1 and PEX-si groups. Compared with the control group, the expression levels of the pro-inflammatory factors IFN- $\gamma$ and IL-12 was significantly increased in the siMALAT1 and PEX-si groups $(P<0.05, P=0.000)$, while those of IL-10 and TGF- $\beta$ were significantly decreased $(P<0.05, P=0.000)$. The opposite was observed in the PEX and PEXN groups $(P<0.05, P=0.000)$, suggesting that LLCderived exosomes inhibited inflammatory response (Figure 6C).

\section{LLC-Derived Exosomes Promoted DC Autophagy}

The formation of autophagic vacuoles in DCs was visualized by TEM. More autophagic vacuoles were observed in the PEX and PEXN groups than in the control, NC, PEX-si, and siMALAT1 groups (Figure 7A). To further clarify the effect of LLC-derived exosomes on DC autophagy, the expression of autophagy-related proteins was evaluated (Figure 7B). Compared with the control group, the expression of LC3I/II, Beclin-1, and p62 was significantly increased in the PEX and PEXN groups $(P<0.05$, $P=0.000)$, and siMALAT1 and PEX-si showed the opposite trend $(P<0.05, P=0.000)$. These results revealed that LLC-derived exosomes promoted DC autophagy.
A

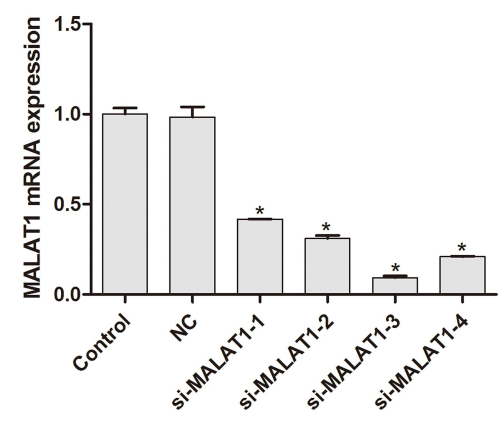

B

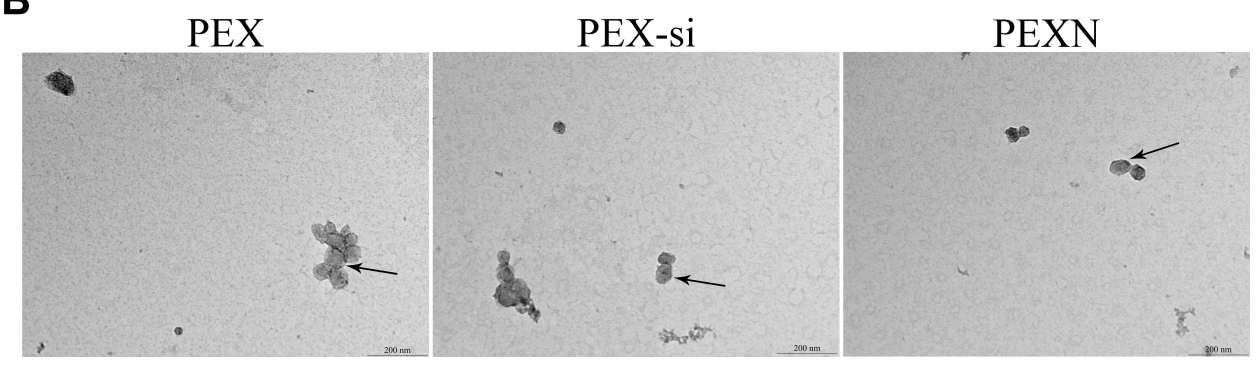

C

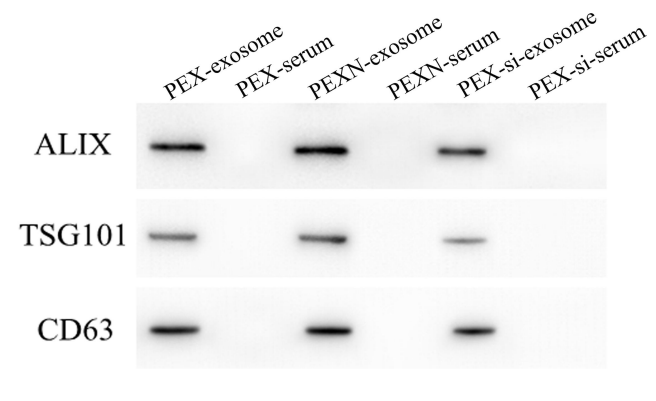

Figure 3 Controls for interference expression. (A) MALATI expression in Control, NC, and si-MALATI (I-4) groups. (B and C) Identification of exosomes in PEX, PEX-si, and PEXN groups by Western blot and TEM (scale bar $=500 \mathrm{~nm}$ ). Arrows indicate exosomes. *P $<0.05$ vs Control. 
A

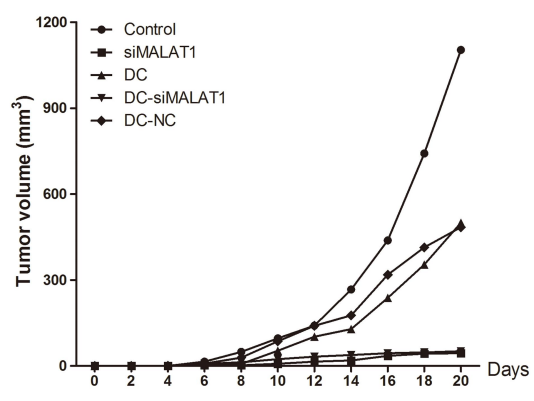

B

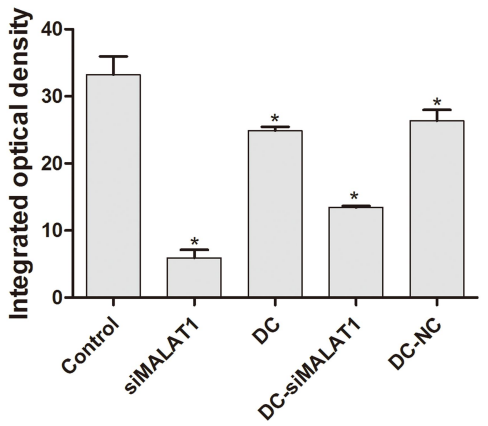

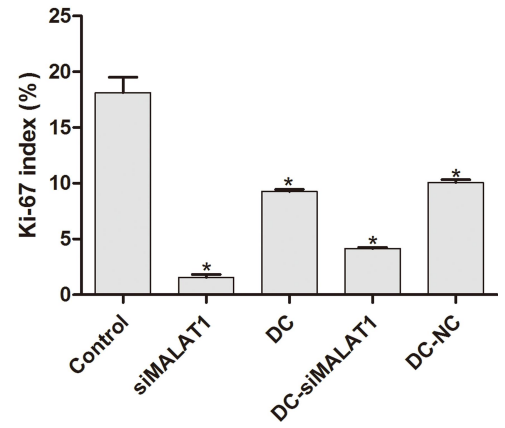

Figure 4 In vivo detection of tumor volume and proliferation. (A) Tumor volume was measured every two days and the inhibitory effect of siMALATI increased with time. (B) Tumor proliferation was observed by Ki-67 staining. The results are presented as the mean \pm SD, $n=3$. *P $<0.05$ vs Control.

A

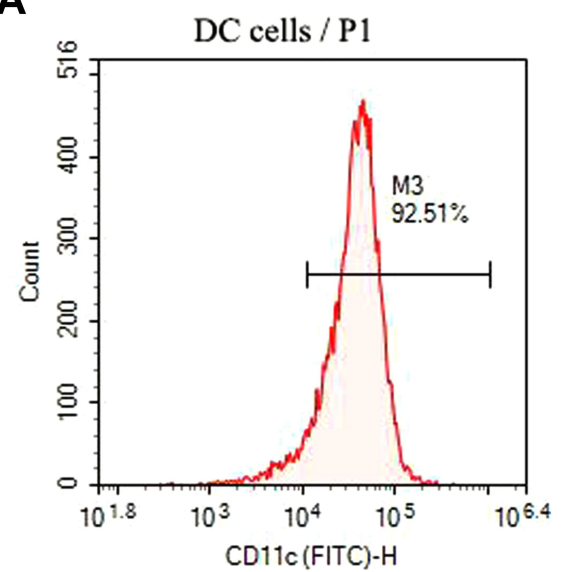

B

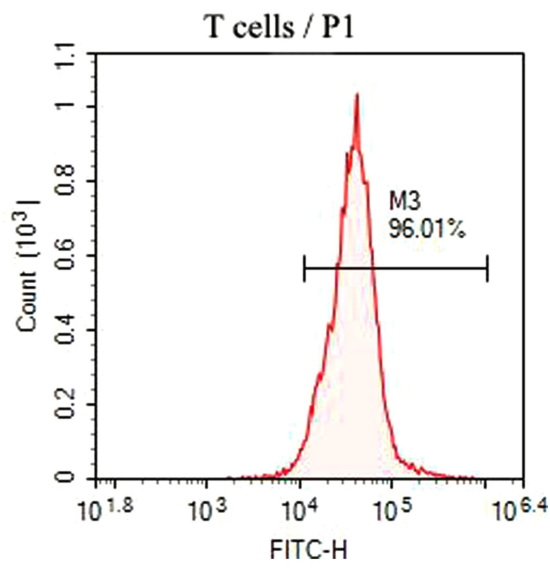

Figure 5 Identification of DCs and T cells. (A and B) The purity of DC and T cells was measured by flow cytometry.

\section{LLC-Derived Exosomes Promoted T Cell Differentiation and Inhibited $\mathrm{T}$ Cell Proliferation}

The effect of LLC-derived exosomes on the DC-mediated regulation of $\mathrm{T}$ cell proliferation and differentiation was investigated by flow cytometry. Compared with the control, T cell proliferation was increased in the siMALAT1 and PEX-si groups $(\mathrm{P}<0.05$, $P=0.000)$, while that in the PEX and PEXN groups was decreased $(P<0.05, P=0.000)$. The change in T cell proliferation was not related to the DC:T ratio (Figure $8 \mathrm{~A}$ ). Compared with the control group, the Treg ratio in the PEX and PEXN groups was increased significantly $(P<0.05, P=0.000)$, while that in the siMALAT1 and PEX-si groups was decreased $(P<0.05, P=0.000)$ (Figure $8 \mathrm{~B})$.

\section{Effect of LLC-Derived Exosomes on AKT/mTOR Pathway}

To investigate the influence of LLC-derived exosomes on the AKT/mTOR pathway in DCs, we measured the protein expression of $\mathrm{p}$-AKT, AKT, p-mTOR, and mTOR using Western blot (Figure 9). The protein expression levels of p-AKT, AKT, p-mTOR, and mTOR in the PEX and PEXN groups were increased compared with those in the control, while those in the siMALAT1 and PEX-si groups were significantly decreased $(\mathrm{P}<0.05, P=0.000)$.

\section{Discussion}

MALAT1, located on human chromosome 11q13, is an intergenic transcript with a length of approximately $8 \mathrm{~kb}$. It is highly conserved in mammalian evolution and the homology of its nucleotide sequence at the $3^{\prime}$ terminal of $5 \mathrm{~KB}$ between human and mouse is as high as $90 \%$. The RNA processing factors RNPS1, SRm160, and IBP160 were found to specifically induce the localization of MALAT1 in nuclear speckles. After siRNA interference, MALAT1 is dispersed into the nucleus and loses its regulatory function on gene expression. MALAT1 also participates in pre-mRNA modification and 
A

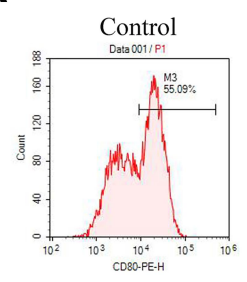

\begin{tabular}{ll} 
Gate & $\% \mathrm{P} 1$ \\
\hline $\mathrm{P} 1$ & $100.00 \%$ \\
$\mathrm{M} 3$ & $5500 \%$
\end{tabular}

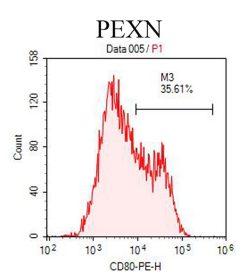

\begin{tabular}{ll} 
Gate & $\%$ P1 \\
\hline P1 & $100.00 \%$ \\
M3 & $35.61 \%$
\end{tabular}
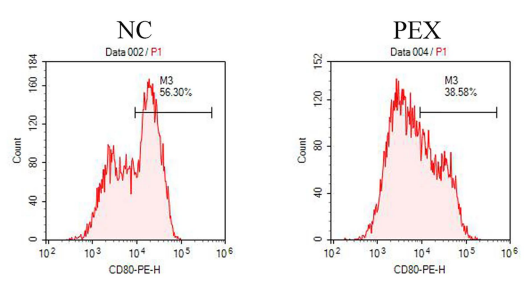

\begin{tabular}{ll} 
Gate $\% \mathrm{P}$ \\
\hline $\mathrm{P} 1$ & $100.00 \%$ \\
$\mathrm{M} 3$ & $56.00 \%$
\end{tabular}

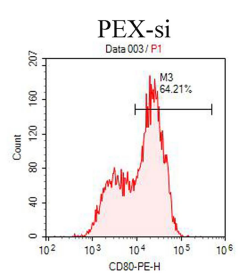

\begin{tabular}{ll} 
Gate & $\% \mathrm{P} 1$ \\
\hline $\mathrm{P} 1$ & $100.00 \%$ \\
$\mathrm{M} 3$ & $64.21 \%$
\end{tabular}

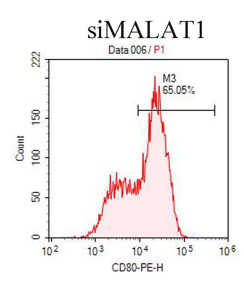

\begin{tabular}{ll} 
Gate & $\% P_{1}$ \\
\hline P1 & $100.00 \%$ \\
M3 & $65.05 \%$
\end{tabular}
B
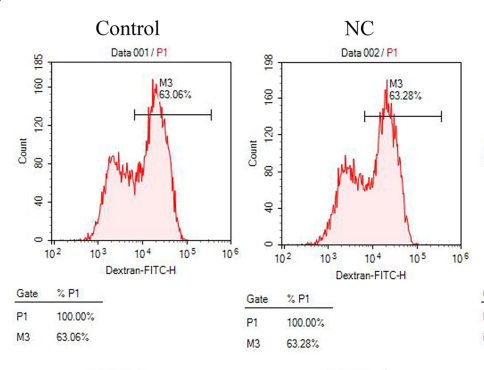

\begin{tabular}{ll} 
Gate & $\%$ P 1 \\
\hline P1 & $100.00 \%$ \\
M3 & $63.28 \%$
\end{tabular}

M3 $\quad 63.28 \%$
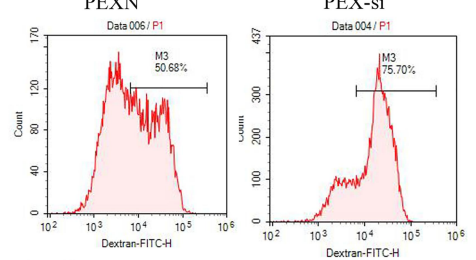

\begin{tabular}{ll} 
Gate & $\%$ P1 \\
\hline P1 & $100.00 \%$ \\
M3 & $50.08 \%$
\end{tabular}

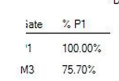

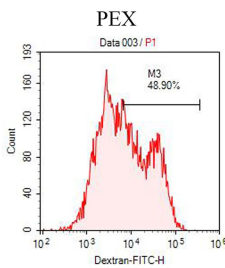

\begin{tabular}{ll} 
Gate & $\% \mathrm{P} 1$ \\
\hline P1 & $100.00 \%$ \\
M3 & $48.00 \%$
\end{tabular}

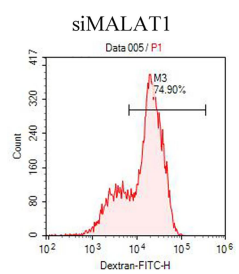

\begin{tabular}{ll} 
Gate & $\% \mathrm{P} 1$ \\
\hline $\mathrm{P} 1$ & $100.00 \%$ \\
$\mathrm{M} 3$ & $74.00 \%$
\end{tabular}

\section{C}

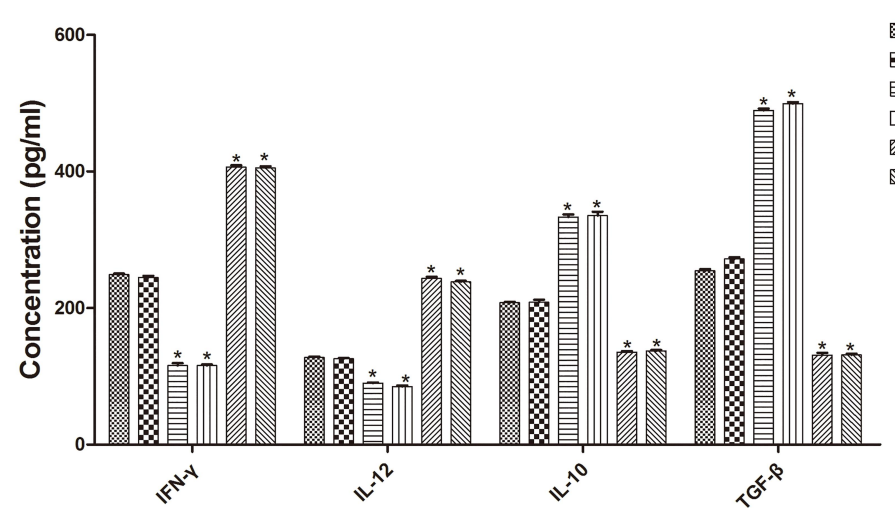

Figure 6 Effect of LLC-derived exosomes on DC phagocytosis, inflammatory response, and costimulatory molecule expression. (A and B) Cell phagocytosis and CD80 expression were observed by flow cytometry. (C) Levels of IFN- $\gamma$, IL-I2, IL-10, and TGF- $\beta$ were observed by ELISA. The results are presented as the mean \pm SD, $n=3$. $* \mathrm{p}<0.05$ vs Control.

splicing by recruiting multiple splicing factors to the transcript activation site, thereby regulating gene expression at the post-transcriptional level. ${ }^{30}$ MALAT1 is abnormally expressed in many human tumor tissues and has the function of altering the biological phenotype of tumor cells, promoting tumor cell proliferation, metastasis, and invasion. Schmidt et al. ${ }^{31}$ found that the expression of MALAT1 in non-small cell lung cancer was significantly higher than that in adjacent normal tissues. After siRNA interference, the migration ability of lung cancer cells and the tumorigenic ability of nude mice were significantly reduced, indicating that MALAT1 is capable of promoting lung tumor formation. After MALAT1 expression was silencing with siRNA, Tano et al found that lung cancer cell migration was significantly reduced. ${ }^{32}$ In our study, we found that the expression of MALAT1 in lung cancer cells was much higher than that in normal lung epithelial cells in vitro and in vivo. Inhibiting the expression of MALAT1 significantly reduced the tumorigenicity of nude mice.

Exosomes are the most well-defined vesicles thus far. Intracellular lysin microparticles are invaginated to form polyvesicles, which fuse with the cell membrane under external stimulation and secrete exosomes with diameters of 50-200 nm to the exterior of the cell. Because of their special formation mode, exosomes do not contain proteins in the endoplasmic reticulum but express high levels of endogenous proteins such as ALIX and TSG101. Exosomes are specifically recognized by target cells in three main ways. ${ }^{33}$ They can directly fuse with the cell membrane to release mRNAs, which enter the cytoplasm; they can be ingested by target cells through endocytosis; and they can recognize specific antibodies on the cell 


\section{A}
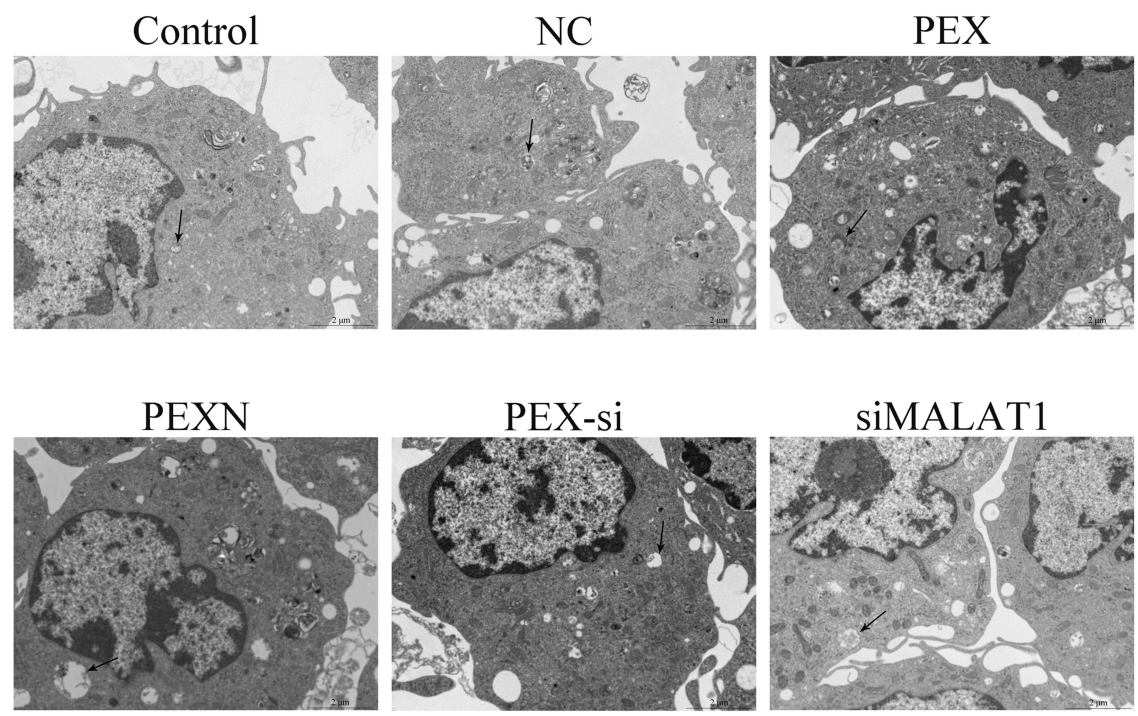

B

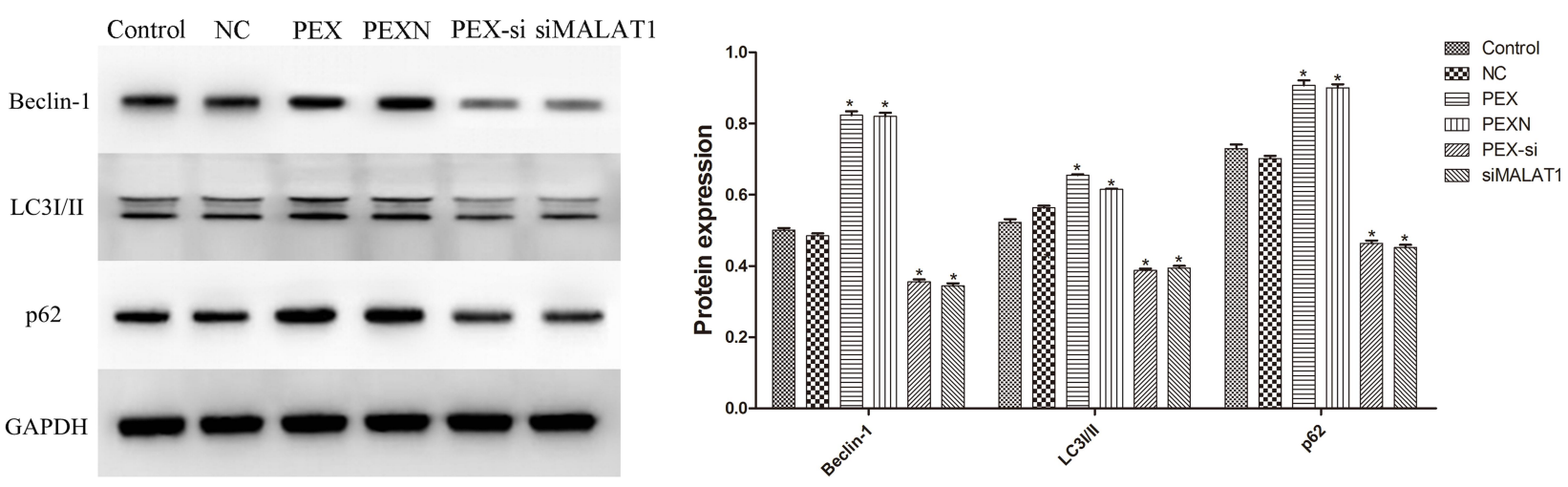

Figure 7 Effect of LLC-derived exosomes on DC autophagy. (A) Autophagic vacuoles were detected by TEM (scale bar $=2 \mu \mathrm{m}$ ). The black arrows represent autophagic vacuoles. (B) Autophagy-related proteins were examined by Western blot. The results are presented as the mean $\pm S D, n=3$. $* P<0.05$ vs Control.

surface. Exosomes are an important means for cancer cells to alter the tumor microenvironment and even transfer to other tissues and organs. ${ }^{34,35}$ Both normal and cancer cells produce exosomes, but secretion from cancer cells is significantly higher and the types of molecules carried by exosomes are different from those secreted by normal cells. Studies have shown that under hypoxia, the number of exosomes secreted by breast cancer cells increased significantly, and exosomes inhibited the proliferation of $\mathrm{T}$ cells, thereby improving the immunosuppressive effect of the tumor microenvironment. ${ }^{36}$ Cheng et al found that exosomes from M1-polarized pro-inflammatory macrophages were mainly absorbed by macrophages and DCs in vivo, thus inducing T cell response. ${ }^{37}$ Numerous studies have shown that tumor cell-derived exosomes stimulated DC maturation, ${ }^{38}$ which is accompanied by the upregulation of major histocompatibility complex (MHC) molecules and costimulatory molecules. DCs exhibit an effective immunogenic phenotype, which is characterized by the release of IL-12, ${ }^{39}$ and secrete IL-12 to trigger immune response dominated by potent $\mathrm{T}$ (Th1) and cytotoxic T lymphocytes. ${ }^{40}$ The costimulatory molecule CD 80 plays an important role in inducing in vivo anti-tumor immunity, which mainly corresponds to $\mathrm{T}$ cell-mediated cellular immunity. CD80 binds to CD28 on the surface of $\mathrm{T}$ cells to enhance costimulatory signaling and promote $\mathrm{T}$ cell activation. In this study, LLC-derived exosomes exerted immunosuppressive effect by suppressing the expression of CD80, inhibiting phagocytic function and inflammatory response, and promoting DC autophagy. When MALAT1 was inhibited in LLC-derived exosomes, the above phenomena were suppressed, suggesting that the effect of exosomes on DC function is related to the abnormal expression of MALAT1. 


\section{A}
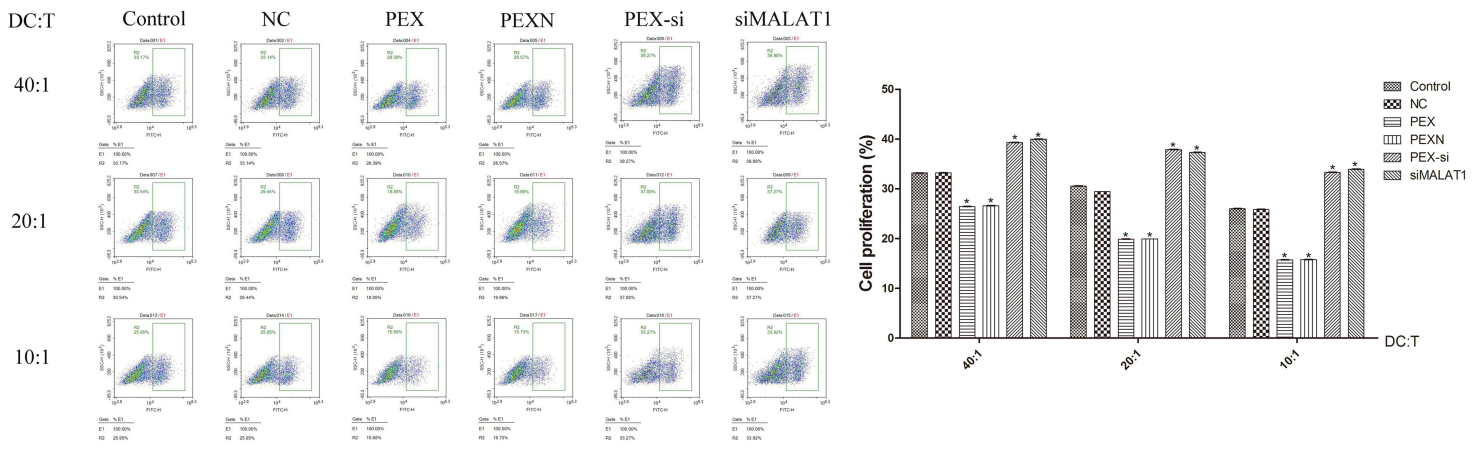

B
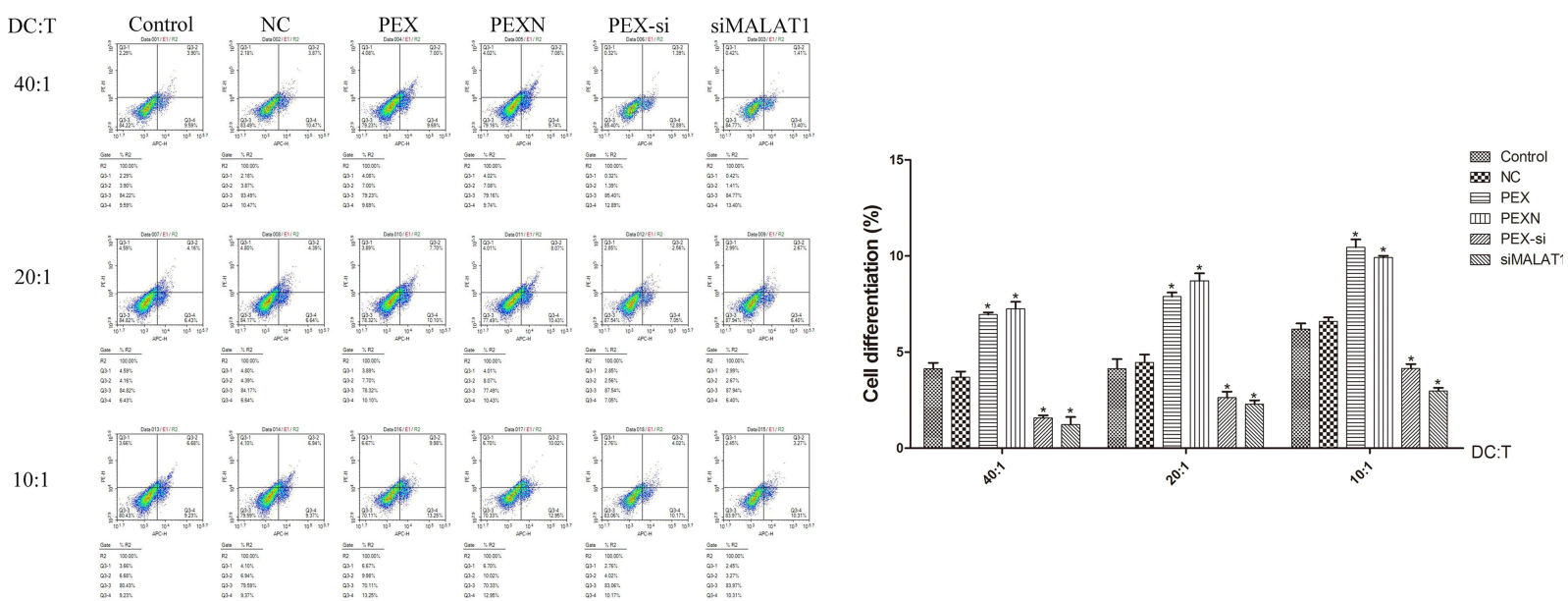

Figure 8 Effect of LLC-derived exosomes on T cell proliferation and differentiation. (A) Proliferation and (B) differentiation of T cells were detected by flow cytometry. The results are presented as the mean $\pm S D, n=3$. $* P<0.05$ vs Control.
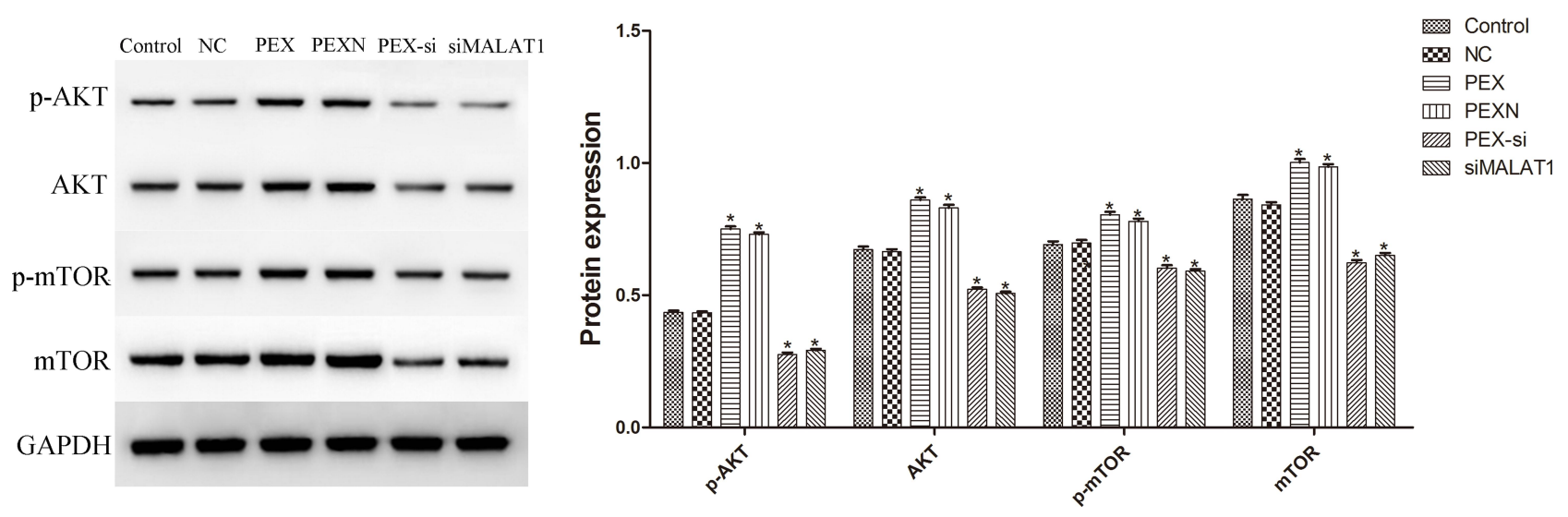

Figure 9 Effect of LLC-derived exosomes on AKT/mTOR pathway. The results are presented as the mean \pm SD, $n=3 . * \mathrm{P}<0.05$ vs Control.

DCs are antigen-presenting cells that stimulate the proliferation of naive $\mathrm{T}$ cells and are the initiator of the body's immune response. Mature DCs not only present exogenous antigens to $\mathrm{T}$ helper cells via the MHC II molecular pathway, but also present antigenic peptide segments to cytotoxic T cells via alternative MHC I molecular pathways. ${ }^{41,42} \mathrm{~T}$ cell activation mainly consists of two parts. First, DCs present antigens to $\mathrm{T}$ cells, or $\mathrm{T}$ cells directly recognize specific antigens to promote the expression of costimulatory molecules in DCs. Second, active molecules expressed by DCs activate T cells through the co-action of CD28/CTLA-4 and threshold TCR, thus inducing immune response. In addition to activating $\mathrm{T}$ cells, DCs play an important role in the peripheral immune 
tolerance of T cells. ${ }^{43}$ When DCs interact with T cells for a long time and are stable, they promote $\mathrm{T}$ cell proliferation, but when the interaction between the two is transient and unstable, DCs induce $\mathrm{T}$ cell differentiation and promote $\mathrm{T}$ cell apoptosis. ${ }^{44}$ In this study, after DCs were cocultured with LLC-derived exosomes, T cell proliferation was significantly inhibited while differentiation was promoted, and this trend was reversed by MALAT1 inhibition. It is suggested that LLC-derived exosomes inhibited the proliferation and promoted the differentiation of $\mathrm{T}$ cells, which may be related to the expression of MALAT1 in the exosomes. Whether MALAT1 affects the interaction time and stability of DCs and T cells remains to be confirmed by further experiments in subsequent studies.

Autophagy, also known as type II programmed cell death, is a biological process characterized by the presence of long-lived proteins encapsulated by bilayer membrane structures and organelle autophagosomes in the cytoplasm. As an intracellular degradation process, autophagy is critical for the survival of eukaryotic cells and mammals. In tumor cells, autophagy is regulated by a variety of signaling pathways, ${ }^{45}$ among which the AKT/mTOR pathway is the most common and regulates tumor cell growth and proliferation while inhibiting autophagy. AKT, the central molecule of the AKT/mTOR signaling pathway, promotes protein synthesis and cell growth by inhibiting TSC1/2 and activating mTOR and regulates cell proliferation by inactivating cell cycle inhibitors. Under growth conditions, the AKT/mTOR signaling pathway regulates cell growth and survival, whereas under stress, the mTOR pathway is inhibited, autophagosomes are formed, and autophagy is ultimately induced. ${ }^{46}$ Studies have shown that the use of RAD001 as an inhibitor of the mTOR pathway induced autophagy, thereby promoting tumor survival and combating anti-tumor effects. ${ }^{47}$ Cancer cells also promote autophagy in surrounding cells to degrade their own proteins and release amino acids for further growth and proliferation of cancer cells. ${ }^{48}$ In this study, LLC-derived exosomes promoted the activity of AKT/mTOR in DCs. Previous experiments have shown that LLC-derived exosomes promoted DC autophagy, suggesting that the effect of LLCderived exosomes on DC function may be mediated by the mTOR/AKT signaling pathway.

\section{Conclusion}

LLCs secrete exosomal MALAT1 to inhibit DC function and $\mathrm{T}$ cell proliferation, while promoting DC autophagy and $\mathrm{T}$ cell differentiation. MALAT1 may be a key molecule affecting the function of DCs in LLCs. Inhibition of MALAT1 in LLC-derived exosomes promoted DC phagocytosis, inflammatory response, costimulatory molecule expression, and $\mathrm{T}$ cell proliferation but suppressed $\mathrm{DC}$ autophagy and $\mathrm{T}$ cell differentiation. The findings suggest that MALAT1 inhibition may be a potential strategy for the clinical treatment of lung cancer.

\section{Acknowledgments}

This work was financially supported by National Natural Sciences Foundation of China (Grants 81772499, 81572287, 81974088); Health Commission of Hubei Province Scientific Research Project (WJ2017M142); Natural Science Foundation of Hubei Province (No.2017CFB555) and Foundation of Chinese Society of Clinical Oncology (CSCO:Y-HS2019-39, Y-MX2016-048).

\section{Disclosure}

The authors report no conflicts of interest in this work.

\section{References}

1. Siegel R, Naishadham D, Jemal A. Cancer statistics for hispanics/ latinos, 2012. CA Cancer J Clin. 2012;62(5):283-298. doi:10.3322/ caac. 21153

2. Siegel RL, Miller KD, Jemal A. Cancer statistics, 2016. CA Cancer J Clin. 2016;66(1):7-30. doi:10.3322/caac.21332

3. Hanahan D, Weinberg RA. Hallmarks of cancer: the next generation. Cell. 2011;144(5):646-674. doi:10.1016/j.cell.2011.02.013

4. Chen DS, Mellman I. Oncology meets immunology: the cancer-immunity cycle. Immunity. 2013;39(1):1-10. doi:10.1016/j. immuni.2013.07.012

5. Marta R, Javier S, Alberto H, et al. Exosomes enriched in stemness/ metastatic-related mRNAS promote oncogenic potential in breast cancer. Oncotarget. 2015;6(38):40575-40587. doi:10.18632/oncotarget. 5818

6. Song X, Ding Y, Liu G, et al. Cancer cell-derived exosomes induce mitogen-activated protein kinase-dependent monocyte survival by transport of functional receptor tyrosine kinases. J Biol Chem. 2016;291(16):8453-8464. doi:10.1074/jbc.M116.716316

7. Bruno S, Grange C, Deregibus MC, et al. Mesenchymal stem cell-derived microvesicles protect against acute tubular injury. $J \mathrm{Am}$ Soc Nephrol. 2009;20(5):1053. doi:10.1681/ASN.2008070798

8. Lai RC, Arslan F, Lee MM, et al. Exosome secreted by MSC reduces myocardial ischemia/reperfusion injury. Stem Cell Res. 2010;4 (3):214-222. doi:10.1016/j.scr.2009.12.003

9. Young RS, Ponting CP, Lindsay MA, Griffiths-Jones S. Identification and function of long non-coding RNAs. Essays Biochem. 2013;54 (54):113-126. doi:10.1042/bse0540113

10. Kornienko AE, Guenzl PM, Barlow DP, et al. Gene regulation by the act of long non-coding RNA transcription. BMC Biol. 2013;11(1):59. doi:10.1186/1741-7007-11-59

11. Shi X, Sun M, Liu H, et al. Long non-coding RNAs: a new frontier in the study of human diseases. Cancer Lett. 2013;339(2):159-166. doi:10.1016/j.canlet.2013.06.013 
12. Mercer TR, Mattick JS. Structure and function of long noncoding RNAs in epigenetic regulation. Nat Struct Mol Biol. 2013;20(3):300. doi: $10.1038 / \mathrm{nsmb} .2480$

13. Wang F, Xie C, Zhao W, et al. Long non-coding RNA CARLo-5 expression is associated with disease progression and predicts outcome in hepatocellular carcinoma patients. Clin Exper Med. 2015;17(1):1-11.

14. Zhang Y, Zhang P, Wan X, et al. Downregulation of long non-coding RNA HCG11 predicts a poor prognosis in prostate cancer. Biomed Pharmacother. 2016;83:936-941. doi:10.1016/j.biopha.2016.08.013

15. Gao X, Wen J, Gao P, Zhang G, Zhang G. Overexpression of the long non-coding RNA,linc-UBC1, is associated with poor prognosis and facilitates cell proliferation, migration, and invasion in colorectal cancer. Oncotargets Ther. 2017;10:1017-1026. doi:10.2147/OTT.S129343

16. Tian $\mathrm{X}, \mathrm{Xu} \mathrm{G}$. Clinical value of 1 ncRNA MALAT1 as a prognostic marker in human cancer: systematic review and meta-analysis. $B M J$ Open. 2015;5(9):e008653. doi:10.1136/bmjopen-2015-008653

17. Zhang $\mathrm{P}$, Zhou $\mathrm{H}$, Lu $\mathrm{K}$, et al. Exosome-mediated delivery of MALAT1 induces cell proliferation in breast cancer. Oncotargets Ther. 2018;11:291-299. doi:10.2147/OTT.S155134

18. Zhang W, Zhou Y, Ding Y. Lnc-DC mediates the over-maturation of decidual dendritic cells and induces the increase in Th1 cells in preeclampsia. Am J Reprod Immunol. 2017;77(6):e12647. doi:10.1111/ aji. 12647

19. Wang P, Xue Y, Han Y, et al. The STAT3-binding long noncoding RNA lnc-DC controls human dendritic cell differentiation. Science. 2014;344(6181):310-313. doi:10.1126/science.1251456

20. Patel NA, Moss LD, Lee JY, et al. Long noncoding RNA MALAT1 in exosomes drives regenerative function and modulates inflammation-linked networks following traumatic brain injury. J Neuroinflamm. 2018;15(1):204. doi:10.1186/s12974-018-1240-3

21. Huang C, Han J, Wu Y, et al. Exosomal MALAT1 derived from oxidized low-density lipoprotein-treated endothelial cells promotes M2 macrophage polarization. Mol Med Rep. 2018. doi:10.3892/mmr.2018.8982

22. Kuma A, Hatano M, Matsui M, et al. The role of autophagy during the early neonatal starvation period. Nature. 2004;432 (7020):1032-1036. doi:10.1038/nature03029

23. Deretic V. Autophagy in innate and adaptive immunity. Trends Immunol. 2005;26(10):523-528. doi:10.1016/j.it.2005.08.003

24. Chen J, Wang S, Jia S, et al. Integrated analysis of long non-coding RNA and mRNA expression profile in pancreatic cancer derived exosomes treated dendritic cells by microarray analysis. J Cancer. 2018;9(1):21-31. doi:10.7150/jca.21749

25. Son CH, Bae JH, Shin DY, et al. Antitumor effect of dendritic cell loaded ex vivo and in vivo with tumor-associated antigens in lung cancer model. Immunol Invest. 2014;43(5):447-462. doi:10.3109/ 08820139.2014.884576

26. Xiao L, Erb U, Zhao K, et al. Efficacy of vaccination with tumor-exosome loaded dendritic cells combined with cytotoxic drug treatment in pancreatic cancer. Oncoimmunology. 2017;6(6): e1319044. doi:10.1080/2162402X.2017.1319044

27. Jiang T, Chen X, Zhou W, et al. Immunotherapy with dendritic cells modified with tumor-associated antigen gene demonstrates enhanced antitumor effect against lung cancer. Transl Oncol. 2017;10 (2):132-141. doi:10.1016/j.tranon.2016.12.002

28. Tang Y, Xiao G, Chen Y, et al. LncRNA MALAT1 promotes migration and invasion of non-small-cell lung cancer by targeting miR-206 and activating Akt/mTOR signaling. Anticancer Drugs. 2018;1. doi:10.1097/CAD.0000000000000650

29. Wu J, Zhang H, Zheng Y, et al. The long noncoding RNA MALAT1 induces tolerogenic dendritic cells and regulatory T cells miR155/dendritic cell-specific intercellular adhesion molecule-3 grabbing nonintegrin/ IL10Axis. Front Immunol. 2018;9. doi:10.3389/fimmu.2018.01847
30. Tripathi V, Ellis JD, Shen Z, et al. The nuclear-retained noncoding RNA MALAT1 regulates alternative splicing by modulating SR splicing factor phosphorylation. Mol Cell. 2010;39:925-938. doi:10.1016/j.molcel.2010.08.011

31. Schmidt LH, Spieker T, Koschmieder S, et al. The long noncoding MALAT1 RNA indicates a poor prognosis in non-small cell lung cancer and induces migration and tumor growth. J Thorac Oncol. 2011;6:1984-1992. doi:10.1097/JTO.0b013e3182307eac

32. Tano K, Mizuno R, Okada T, et al. MALAT1 enhances cell motility of lung adenocarcinoma cells by influencing the expression of motility-related genes. FEBS Lett. 2010;584:4575-4580. doi:10.1016/j.febslet.2010.10.008

33. Cocucci E, Racchetti G, Meldolesi J. Shedding microvesicles: artefacts no more. Trends Cell Biol. 2009;19(2):43-51. doi:10.1016/j. tcb.2008.11.003

34. Fang T, Lv H, Lv G, et al. Tumor-derived exosomal miR-1247-3p induces cancer-associated fibroblast activation to foster lung metastasis of liver cancer. Nat Commun. 2018;9(1):191. doi:10.1038/ s41467-017-02583-0

35. Nabet BY, Qiu Y, Shabason JE, et al. Exosome RNA unshielding couples stromal activation to pattern recognition receptor signaling in cancer. Cell. 2017;170(2):352-366. doi:10.1016/j.cell.2017.06.031

36. Rong L, Rong LI, Shaoying LI, et al. Immunosuppression of breast cancer cells mediated by transforming growth factor- $\beta$ in exosomes from cancer cells. Oncol Lett. 2016;11(1):500. doi:10.3892/ol.2015.3841

37. Cheng L, Wang Y, Huang L. Exosomes from M1-polarized macrophages potentiate the cancer vaccine by creating a pro-inflammatory microenvironment in the lymph node. Mol Ther. 2017;25(7):1665. doi:10.1016/j.ymthe.2017.02.007

38. Rao Q, Zuo B, Lu Z, et al. Tumor-derived exosomes elicit tumor suppression in murine hepatocellular carcinoma models and humans in vitro. Hepatology. 2016;64(2):456-472. doi:10.1002/hep.28549

39. Felzmann T, Katharina Gabriele H, Breuer SK, et al. Semi-mature IL-12 secreting dendritic cells present exogenous antigen to trigger cytolytic immune responses. Cancer Immunol Immunother. 2005;54 (8):769-780. doi:10.1007/s00262-004-0637-2

40. Lee JJ, Foon KA, Mailliard RB, et al. Type 1-polarized dendritic cells loaded with autologous tumor are a potent immunogen against chronic lymphocytic leukemia. J Leukoc Biol. 2008;84(1):319-325. doi:10.1189/jlb.1107737

41. Banchereau J, Steinman RM. Dendritic cells and the control of immunity. Nature. 1998;392(6673):245-252. doi:10.1038/32588

42. Grewal IS, Foellmer HG, Grewal KD, et al. Requirement for CD40 ligand in costimulation induction, T cell activation, and experimental allergic encephalomyelitis. Science. 1996;273(5283):1864-1867. doi:10.1126/science.273.5283.1864

43. Stoll S, Delon J, Brotz TM, et al. Dynamic imaging of $T$ cell-dendritic cell Interactions in lymph nodes. Science. 2002;296 (5574):1873-1876. doi:10.1126/science.1071065

44. Gu CY, Zheng L, Wang Q. Research progress on mechanism and application of dendritic cells in the treatment of autoimmune diseases. Curr Immunol. 2005;25(3):253-255.

45. Prieto-Domínguez N, Ordóñez R, Fernández A, et al. Modulation of autophagy by sorafenib: effects on treatment response. Front Pharmacol. 2016;7. doi:10.3389/fphar.2016.00151

46. Sun SY. Enhancing perifosine's anticancer efficacy by preventing autophagy. Autophagy. 2010;6(1):184-185. doi:10.4161/auto.6.1.10816

47. Lin JF, Lin YC, Tsai TF, et al. Autophagy inhibition enhances RAD001-induced cytotoxicity in human bladder cancer cells. Drug Des Dev Ther. 2016;1501. doi:10.2147/DDDT.S95900

48. Katheder NS, Khezri R, O'Farrell F, et al. Microenvironmental autophagy promotes tumour growth. Nature. 2017;541 (7637):417-420. doi:10.1038/nature20815 


\section{Publish your work in this journal}

OncoTargets and Therapy is an international, peer-reviewed, open access journal focusing on the pathological basis of all cancers, potential targets for therapy and treatment protocols employed to improve the management of cancer patients. The journal also focuses on the impact of management programs and new therapeutic

Submit your manuscript here: https://www.dovepress.com/oncotargets-and-therapy-journal agents and protocols on patient perspectives such as quality of life, adherence and satisfaction. The manuscript management system is completely online and includes a very quick and fair peer-review system, which is all easy to use. Visit http://www.dovepress.com/ testimonials.php to read real quotes from published authors. 